\title{
FLEXIBLE NEPHROSCOPY: A STEP TOWARDS COMPLETE STONE CLEARANCE IN PCNL
}

Vasudevan Thirugnanasambandam, Kalyanram Kone

Department of Urology, Mahatma Gandhi Medical College and Research Institute, Sri Balaji Vidyapeeth, Pondicherry, India

Corresponding Author: akashlaya@gmail.com

Received: 27 October 2020; Accepted after revision: 14 December 2020;

Published: 18 January 2021.

\begin{abstract}
\section{Objectives}

To determine the usefulness of flexible nephroscopy after per-cutaneous nephrolithotomy (PCNL) in detecting residual fragments.

\section{Materials and Methods}

A prospective study was conducted between January 2018 and December 2019 on patients undergoing standard PCNL using a flexible nephroscope to inspect all the calyces for residual stones. When residual stones were noted, either they were removed by basketing or by performing additional puncture to ensure complete clearance. Patients were followed up for 6 months and at the end of 1 month a plain CT KUB was done to look for residual fragments.
\end{abstract}

\section{Results}

The study cohort included 212 patients. Significant RFs were found in 28 patients during flexible nephroscopy and in two patients at 1 month follow up CT scan. All patients were stone free during 6 months follow up.

\section{Conclusion}

Flexible nephroscopy during PCNL decreases the chance of residual fragments and thereby reducing the chance of re-procedure rates.

Keywords: flexible nephroscope; PCNL; residual fragments

\section{INTRODUCTION}

The management of kidney stones has evolved over the years from the era of cutting open for stones to the minimally invasive techniques available today thereby reducing the hospital stay and faster recovery. In present day situation, most of the stones in kidney are managed endourologically.
The current guidelines recommend per-cutaneous nephrolithotomy (PCNL) for the management of renal stones larger than $2 \mathrm{cms}$ and lower pole stones larger than $15 \mathrm{~mm}{ }^{1}$

PCNL is time tested and offers stone free rates (SFR) in the range between 70 and $85 \%$ in various studies. ${ }^{2}$ The central dogma of treatment for renal 
stones is complete clearance without any residual fragments. If any residual fragments remain after surgery, they may cause symptoms and there will be a need for additional ancillary procedures which burden the patient. So it is best in the interest of the patient to do away with as minimal procedure as deemed possible.

The term SFR is a guarded statement as the meaning varies according to different studies because of the phrase "clinically insignificant residual fragments" (CIRF). The definition of CIRF is any fragment less than or equal to $4 \mathrm{~mm}$ which means the patient in reality is not stone free. ${ }^{3,4}$ Because of this CIRF, many studies have credited themselves for rendering patients stone free. ${ }^{5}$

Moreover, it is found that fragments larger than $2 \mathrm{~mm}$ left behind after surgery can lead to symptoms propelling them for second procedure. ${ }^{6}$ So the definition of "insignificant fragments" needs a revisit as there is no proper consensus statement currently available.

Conventionally, plain X-ray KUB and ultrasound are used to look for residual fragments because of their lower cost and availability. Even today, most centres rely on these methods as they are readily available and patients' exposure to radiation is less when compared to $\mathrm{CT}$, $^{7,8,9}$

In one of the studies conducted by Pires et al., ${ }^{10}$ they have found that plain CT has $100 \%$ sensitivity in ruling out residual fragments when compared with traditional X-ray which has only $87 \%$ sensitivity in detecting stone fragments less than $5 \mathrm{~mm}$. So, when it comes to a trade-off between radiation and residual fragments, even though radiation is a problem with $\mathrm{CT}$, it is wise to choose this modality to detect stone fragments. ${ }^{10}$

Whatsoever, residual fragments are both physically and mentally problematic to the patient as these can re-grow and form a nidus for recurrent urinary tract infection (UTI). ${ }^{11}$

With this preamble, what needs to be seen is how to minimise the chance of leaving behind stone fragments. There are various factors which need to be attended in order to achieve stone-free status. The first factor is proper choice of lithotripter. It is shown that the use of ultrasonic lithotripter with suction can minimise the chance of stone fragment migration. The second one is the use of laser energy for fragmentation. The third is the use of intra-operative ultrasound and Carm combination to look for residual fragments. With these entire manoeuvres, one can reduce the chance of residual fragments but not completely eliminate the probability of leaving them behind. As the old saying goes, "When you can see with your eyes, it exists" holds good for looking for residual fragments under direct vision using a flexible nephroscope. There are only few published studies on flexible nephroscopy after PCNL. ${ }^{12}$

In this study, we did flexible nephroscopy after PCNL in each case in an effort to look for residual fragments.

\section{MATERIALS AND METHODS}

A prospective observational study was conducted between Dec 2018 and Dec 2019 in patients undergoing PCNL for renal stones larger than $2 \mathrm{cms}$. An informed and written consent was taken from all the patients explaining that flexible nephroscopy will be done at the end of surgery to look for residual fragments of stone. A total of 256 patients underwent PCNL for renal stones. After exclusion, 212 patients were included in the study. Standard prone PCNL was performed in all patients under fluoroscopy guidance. Amplatz sheath size varied from $18 \mathrm{Fr}$ to $24 \mathrm{Fr}$. After completion of procedure, $\mathrm{C}$-arm imaging was performed to look for any radio-opaque fragments. Once it was ensured that no visible fragments were noted, using 15.5 Fr Karl Storz Flexible nephroscope with c-arm guidance, an endoscopy was done through the amplatz sheath inspecting all the reachable calyces for any residual fragments. If residual fragments were identified, they were either basketted or flushed out with saline. In some cases, an additional puncture was made to clear the stone fragments. Once all fragments were cleared to surgeon's satisfaction, DJ stent was placed and a nephrostomy tube was placed. On the first post-operative day, a digital X-ray and a USG was done. Nephrostomy tube was removed if there was no fever, bleeding or residual fragments in Xray. After 15 days, a plain CT KUB was taken. Once stone clearance was ensured, stent was removed. If any residual fragments were noted, depending upon the location of the fragments they were observed for spontaneous expulsion, extracorporeal shock wave

J Endolum Endourol Vol 4:e13-e16; January 18, 2021.

This article is distributed under the terms of the Creative Commons Attribution-Non Commercial 4.0 International License. (C) Thirugnanasambandam and Kalyanram Kone 
lithotripsy (ESWL) or retrograde intrarenal surgery (RIRS) to achieve complete stone clearance.

\section{RESULTS}

The patient demographics are given in Table 1 . All PCNL procedures were done in prone position. Out of the 212 patients, 152 patients underwent lower calyceal puncture, 44 had middle calyceal puncture and the rest 16 needed superior calyceal puncture. The tract size varied from $18 \mathrm{Fr}$ to $24 \mathrm{Fr}$ size (Table 2). Flexible nephroscopy was done in all cases. Out of the 212 patients, at the end of the procedure when residual fragments were not visualised by $\mathrm{C}$-arm imaging, 28 patients had residual fragments detectable by direct vision by flexible nephroscope. Most common location of the fragments were in lower calyx (16) followed by upper calyx (7) and middle calyx (5). All the lower pole residual fragments were either basketted out (10), laser dusted (4) or flushed out with saline (2) achieving complete clearance. Of the seven upper calyceal fragments, three cases were basketted out, two cases were laser dusted and remaining two cases required another puncture. Out of the five cases in middle calyx, two cases were basketted out, one case was laser dusted and remaining two cases were planned for ESWL at a later date (Table 3).

On the first post-operative day, two patients had residual fragments noted in x-ray and ultrasound. Most probably, these fragments were missed during nephroscopy; either one of the calyx was not accessible because of acute angle or may have been camouflaged by blood clots. Both the patients were counselled to follow up for 1 month and to wait for probability of spontaneous expulsion. During the 1-month follow

TABLE 1 Patient Demography.

\begin{tabular}{|l|l|c|}
\hline \multicolumn{2}{|l|}{ Age (yrs) } & $21-65$ \\
\hline \multirow{3}{*}{ Sex } & Male & 128 \\
\cline { 2 - 3 } & Female & 84 \\
\hline \multirow{3}{*}{ Side } & Right & 104 \\
\cline { 2 - 3 } & Left & 108 \\
\hline \multirow{3}{*}{ Stone burden } & Pelvis & 98 \\
\cline { 2 - 3 } & Calyceal & 24 \\
\cline { 2 - 3 } & Staghorn & 30 \\
\hline
\end{tabular}

TABLE 2 Approach to the Stone and Calyx Chosen for Puncture.

\begin{tabular}{|l|l|c|}
\hline Approach & Sub-costal & 162 \\
\cline { 2 - 3 } & Supra-costal & 32 \\
\cline { 2 - 3 } & Combined & 18 \\
\hline \multirow{3}{*}{ Site of entry } & Lower calyx & 152 \\
\cline { 2 - 3 } & Mid calyx & 44 \\
\cline { 2 - 3 } & Upper calyx & 16 \\
\hline
\end{tabular}

up, both the patients were advised plain CT KUB and both the patients had residual fragments of size more than $5 \mathrm{~mm}$ and they were advised ESWL. All patients were stone free during 6 months follow up proven by plain CT scan (Table 4).

\section{DISCUSSION}

The steps and approaches to renal stones are standardised and time tested. It is not uncommon to find residual fragments left behind after PCNL which burdens the patient as well as the operating surgeon, physically and mentally. Moreover, it adds to the cost of the patient for the additional procedure to achieve stone clearance. There is a lot of many evidence in the literature that certain steps during the PCNL can decrease the chance of leaving behind residual stones but none of them are fool proof.

Of all the techniques-like $\mathrm{C}$-arm imaging, ultrasound imaging and flexible nephroscopy available to ensure stone clearance-none is superior to the other in ruling out residual stones because each technique has its own disadvantage. Like in C-arm

TABLE 3 Location and Modes of Treatment for Residual Fragments.

\begin{tabular}{|l|l|c|}
\hline Total number of residual fragments & 28 \\
\hline Location of fragments & Lower calyx & 16 \\
\cline { 2 - 3 } & Middle calyx & 5 \\
\cline { 2 - 3 } & Upper calyx & 7 \\
\hline \multirow{3}{*}{ Treatment method } & Basketting & 15 \\
\cline { 2 - 3 } & Laser & 7 \\
\cline { 2 - 3 } & Flushed out & 2 \\
\cline { 2 - 3 } & ESWL & 2 \\
\cline { 2 - 3 } & Additional puncture & 2 \\
\hline
\end{tabular}

J Endolum Endourol Vol 4:e13-e16; January 18, 2021.

This article is distributed under the terms of the Creative Commons Attribution-Non Commercial 4.0 International License. (C) Thirugnanasambandam and Kalyanram Kone 
TABLE 4 Stone Clearance (out of 212 patients).

\begin{tabular}{|l|l|c|}
\hline Intra-operative & Before nephroscopy & 184 \\
\cline { 2 - 3 } & After nephroscopy & 210 \\
\hline Post-operative period & 15 days & 210 \\
\cline { 2 - 3 } & 30 days & 210 \\
\cline { 2 - 3 } & 180 days & 212 \\
\hline
\end{tabular}

imaging, fragments may be radiolucent; ultrasound in operated patients can be false positive or negative because of blood clots; air interference and flexible nephroscopy may not reach all calyces. Having said that, of the three techniques, direct visualisation of accessible calyces gives us an opportunity to detect as well as treat the residual fragments. Hence, it scores over the other two techniques.

We have used flexible nephroscopy in all cases and found it useful in most if not all cases in reducing the chance of leaving behind stone fragments. Limitation of our study is that it is an observational type and did not provide comparison with standard PCNL as this was our pilot study. In future, conducting a randomised control study will throw more light towards success in eliminating residual fragments during PCNL.

\section{CONCLUSIONS}

Flexible nephroscopy offers a unique advantage of directly visualising the individual calyces after PCNL and there by offering a chance to minimise the chance of leaving behind residual fragments. More randomised studies are required to justify the claim. But this single, small step during PCNL may become a norm in future.

\section{REFERENCES}

1. Türk CKT, Petrik A, Sarica K, Straub M, Seitz C. Guidelines on urolithiasis. Arnhem. Eur Assoc Urol. 2011. Available at: https://uroweb.org/wp-content/ uploads/20-Urolithiasis.pdf

2. de la Rosette J, Assimos D, Desai M, Gutierrez J, Lingeman J, Scarpa R, et al. The Clinical Research Office of the Endourological Society Percutaneous Nephrolithotomy Global Study: Indications, complications, and outcomes in 5803 patients. J Endourol. 2011;25:11-17. http://dx.doi.org/10.1089/end.2010.0424
3. Streem SB, Yost A, Mascha E. Clinical implications of clinically insignificant store fragments after extracorporeal shock wave lithotripsy. J Urol. 1996;155:1186-90. http://dx.doi.org/10.1016/S0022-5347(01)66208-6

4. Delvecchio FC, Preminger GM. Management of residual stones. Urol Clin North Am. 2000;27:347-54. http://dx.doi.org/10.1016/S0094-0143(05)70263-9

5. Park J, Hong B, Park T, Park HK. Effectiveness of non-contrast computed tomography in evaluation of residual stones after percutaneous nephrolithotomy. J Endourol. 2007;21:684-7. http://dx.doi.org/10.1089/ end.2006.0352

6. Raman JD, Bagrodia A, Gupta A, Bensalah K, Cadeddu JA, Lotan Y, et al. Natural history of residual fragments following percutaneous nephrostolithotomy. J Urol. 2009;181:1163-8. http://dx.doi.org/10.1016/j. juro.2008.10.162

7. Feng MI, Tamaddon K, Mikhail A, Kaptein JS, Bellman GC. Prospective randomized study of various techniques of percutaneous nephrolithotomy. Urology. 2001;58:345-50. http://dx.doi.org/10.1016/ S0090-4295(01)01225-0

8. Lim JK, HJ, Chung KH. Cost and effectiveness of different treatment options for renal calculi larger than 2 cm. Korean J Urol. 2002;43:454-8.

9. Lojanapiwat B. Previous open nephrolithotomy: Does it affect percutaneous nephrolithotomy techniques and outcome? J Endourol. 2006;20:17-20. http://dx.doi. org/10.1089/end.2006.20.17

10. Pires C, Machet F, Dahmani L, Irani J, Dore B. Sensitivity of abdominal radiography without preparation compared with computed tomography in the assessment of residual fragments after percutaneous nephrolithotomy. Prog Urol. 2003;13:581-4.

11. Denstedt JD, Clayman RV, Picus DD. Comparison of endoscopic and radiological residual fragment rate following percutaneous nephrolithotripsy. J Urol. 1991;145:703-5. http://dx.doi.org/10.1016/ S0022-5347(17)38429-X

12. Portis AJ, Laliberte MA, Drake S, Holtz C, Rosenberg MS, Bretzke CA. Intraoperative fragment detection during percutaneous nephrolithotomy: Evaluation of high magnification rotational fluoroscopy combined with aggressive nephroscopy. J Urol. 2006;175:162-5. http://dx.doi.org/10.1016/S0022-5347(05)00052-2

J Endolum Endourol Vol 4:e13-e16; January 18, 2021.

This article is distributed under the terms of the Creative Commons Attribution-Non Commercial 4.0 International License. (c) Thirugnanasambandam and Kalyanram Kone 